\title{
Bacterial two-hybrid analysis of the Shewanella oneidensis MR-1 multi- component electron transfer pathway
}

\author{
Jimmy Borloo ${ }^{1}$, Lina De Smet ${ }^{1}$, Jozef J. Van Beeumen ${ }^{1}$, Bart Devreese ${ }^{1 \star}$. \\ ${ }^{1}$ Department of Biochemistry and Microbiology, Ghent University, Laboratory for Protein Biochemistry and Biomolecular Engineering (L- \\ ProBE), K.L. Ledeganckstraat 35, 9000 Ghent, Belgium.
}

Received: 05 December 2010 Accepted: 02 July 2011 Available Online: 25 July 2011

\section{AbSTRACT}

Understanding cellular systems requires profound analysis of the protein interaction networks. Protein interaction mapping is performed mainly by co-purification strategies or two-hybrid systems. Recently, we expanded the tools for analyzing protein-protein interactions in bacteria with a two-hybrid technique based on beta-galactosidase complementation, and demonstrated its potential to explore interactions of membrane systems and to study transient interactions between redox partners (Borloo et al. 2007a). We demonstrate here the functionality of this assay to reveal the interactions within the complex electron transfer chain of the dissimilatory metal reducing bacterium Shewanella oneidensis MR-1. Specifically, we identified the cytoplasmic membrane-bound CymA as a key component, after which the electron transport chain is found to bifurcate towards several periplasmic proteins. It again congregates at the crucial MtrA, which in turn forms an electron transfer complex with the outer membrane localized MtrB and the terminal ferric reductases MtrC and OmcA. These data are complemented by mutant screening and confirm previous kinetic analyses (Borloo et al., 2007b).

Keywords: Shewanella oneidensis; bacterial two-hybrid; protein interactions; beta-galactosidase.

\section{Abbreviations}

NTA nitrilo triacetic acid; FR fumarate reductase; IPTG isopropyl- $\beta$,d-thiogalactopyranoside; ONPG o-nitrophenyl- $\beta$,dgalactose; NIF non-interacting fusion proteins; IF interacting fusion proteins.

\section{Introduction}

Several bacterial strains have been found capable of reducing heavy metals and to link this process to energy generation in order to grow and survive $[1,2]$. One of the most potent and striking examples of such strains is the Gram-negative facultative anaerobe Shewanella oneidensis MR-1 [3]. During anaerobic metal respiration, S. oneidensis MR-1 applies a sophisticated multi-component cascade, often referred to as the 'metal respiratory system' or the 'Mtr respiratory pathway'. This cascade transfers electrons from the cytoplasmic electron pool over the cytoplasmic membrane and periplasm, ultimately to the outer membrane localized terminal metal reductase(s). Many proteins, most of which are multi-haem cytochromes $c$, have been identified and characterized in the past as playing important roles in dissimilatory metal reduction $[4,5]$. Among these proteins is the centrally positioned cytoplasmic membrane-attached tetrahaem cytochrome c CymA [5-7] that collects excess electrons from carbon sources and shuttles them to MtrA, a decahaem periplasmic c-type cytochrome [8]. MtrA facilitates electron transfer to the outer membrane decahaem cytochromes c MtrC and OmcA [9], which are dependent on the non-haem integral outer-membrane protein MtrB for proper localization in the outer membrane [10]. MtrC and OmcA in turn reduce the terminal electron acceptors, which range from organic flavins to iron or manganese oxide, onto chelated iron complexes.

Despite the fact that the Mtr respiratory pathway has already been quite well-documented, some prominent questions remain. Curiously, the Shewanella oneidensis MR -1 genome encodes over 40 c-type cytochromes. It includes

*Corresponding author: Dr. Bart Devreese, Laboratory for Protein Biochemistry and Biomolecular Engineering, Ghent University, K.L. Ledeganckstraat 35, B-9000 Ghent, Belgium. Phone : +32 926452 73. Fax : +32 926453 38. E-mail Adress : bart.devreese@ugent.be 
a number of paralogues, in particular and most interestingly to this study, MtrC (MtrF), MtrA (MtrD) and MtrB (MtrE). It has been shown that the MtrC-OmcA pair is largely responsible for chelated and insoluble iron reduction [1113], but that MtrF is modular with MtrC and even more active than OmcA during flavin reduction in the absence of MtrC [14]. Additionally, Coursolle and Grainick [14] proved that, upon deletion of MtrA, alternative electron flow routes are recruited and that primarily $\mathrm{MtrD}$, and to a lesser extent DmsE (the periplasmic component of the DMSO respiratory system), at least in part take over its function. Furthermore, involvement of the periplasmic iron-induced flavocytochrome IfcA [15], the small tetrahaem cytochrome c (CctA) [16,17], fumarate reductase [18] and the MtrA paralogue MtrD have been shown to be implicated in the Mtr respiratory pathway, indicating that also periplasmic electron shuttling is modular. Even though the key players in anaerobic dissimilatory metal reduction have already been identified, the exact organization of the electron transport chain, that is, which protein interacts with which protein and in what order and stoichiometry, has not yet been elucidated.

In this work we provide crucial insights in the organization of the chelated iron respiration cascade by: i) assaying several well-selected S. oneidensis MR-1 insertion mutants (i.e. which have been shown to be part of the electron transport chain) for their $\mathrm{Fe}(\mathrm{III})$-NTA reduction capacity, thereby verifying and evaluating their importance or redundancy in the involved electron transport chain, and comparing them to other mutant studies, and ii) applying a recently developed $\beta$-galactosidase based bacterial twohybrid system [19] in order to assess the interaction behavior of all previously identified components of the electron transport chain. Finally, we propose a comprehensive model that represents the S. oneidensis MR-1 Mtr respiratory pathway used during chelated metal reduction.

\section{Material and Methods}

\subsection{Bacterial Strains, Plasmids, Media and Growth Conditions}

S. oneidensis MR-1 was originally isolated from Oneida Lake sediments [5] and was obtained from the LMG culture collection (LMG 19005; Ghent, Belgium). The strain MR$1 \mathrm{R}$, used in this study, is a spontaneous rifampicin-resistant mutant of strain MR-1 that was isolated in-house. The $S$. oneidensis MR-1 ccmE, cymA, STC, ifcA, FR, $m \operatorname{tr} A, m \operatorname{tr} B$, $m t r D, m t r E, m t r F, o m c A$ and $o m c B$ disruption mutants, as well as the omcA/omcB, $m \operatorname{trA} / m \operatorname{tr} D, m \operatorname{trB} / m \operatorname{trE}, m \operatorname{trB} / m \operatorname{trF}$ and $o m c B / m t r F$ double mutants, were obtained during a previous study [20]. Escherichia coli strain XL-1 Blue (Stratagene, La Jolla, CA, USA) was used in all subcloning steps, whereas recombination deficient strain JM109 (The Coli Genetic Stock Center, New Haven, CT, USA) was applied in all subsequent cloning experiments. $\beta$-Galactosidase activity tests were performed using E. coli strain MC1061
(The Coli Genetic Stock Center), which lacks the entire lacZ locus.

The pCOLADuet-1 vector $\left(\mathrm{Km}^{\mathrm{R}}\right)$ was obtained from Novagen (Darmstadt, Germany). The $\mathrm{pB} 2 \mathrm{H} \Delta \alpha\left(\mathrm{Cm}^{\mathrm{R}}\right)$ and $\mathrm{pB} 2 \mathrm{H} \Delta \omega\left(\mathrm{Cb}^{\mathrm{R}}\right)$ plasmids were obtained from a previous study [19].

Media and growth conditions for MR-1R and all S. oneidensis mutant cultures were as described previously [11]. E. coli cultures were grown aerobically in Luria Bertani broth on a rotary shaker $(200 \mathrm{rpm})$ at $37^{\circ} \mathrm{C}[21]$. Growth media were supplemented with appropriate antibiotics when necessary, including chloramphenicol $(\mathrm{Cm})$ at $25 \mu \mathrm{g} / \mathrm{mL}$, carbenicillin $(\mathrm{Cb})$ at $100 \mu \mathrm{g} / \mathrm{mL}$, and kanamycin $(\mathrm{Km})$ at $25 \mu \mathrm{g} / \mathrm{mL}$. When required, IPTG (Duchefa, Haarlem, The Netherlands) was added to a final concentration of $20 \mathrm{mM}$.

\subsection{DNA Manipulations}

To allow cytochrome $\mathrm{c}$ maturation in $\mathrm{E}$. coli, the $\mathrm{ccm}$ genes were cloned from the pEC86 vector into the pCOLADuet-1 vector by XbaI-SalI restriction digest. A list of the synthetic oligonucleotides used in this study is presented in Table 1. Oligonucleotides included the restriction sites used to clone the DNA fragments into the vectors. Restriction digests, cloning and DNA electrophoresis were performed using standard techniques. DNA ligations were performed using T4 DNA Ligase (Promega, Madison, WI, USA). Isolation of plasmid DNA was accomplished using the QIAprep Plasmid Midi Kit 100 (Qiagen, Hilden, Germany). All DNA constructs were confirmed by DNA sequencing (GENOME Express, Meylan, France).

\subsection{Fe(III)-NTA Reduction Assay}

S. oneidensis MR-1R and all mutant strains were assayed for $\mathrm{Fe}(\mathrm{III})-\mathrm{NTA}$ reduction activity according to previous reports [11], with the exception that $1.5 \mathrm{mM}$ Fe(III)-NTA was used. Figure 1 presents the results of triplicate experiments.

\section{4 $\beta$-Galactosidase-based Bacterial Two-Hybrid Assay}

All steps in the application of the two-hybrid system, with the exception of protein sample preparation and the enzymatic $\beta$-galactosidase assay, were carried out as previously described [19].

Protein sample preparation was carried out as follows. Cells were centrifuged for 10 minutes at $10,000 \times g$. The pellet was resuspended in $1 \mathrm{~mL}$ phosphate buffered saline (PBS, $\mathrm{pH}$ 7.4) with Complete Protease Inhibitor (Roche Diagnostics Corporation, Indianapolis, IN, USA) (1 tablet per 200 $\mathrm{mL}$ sample), followed by sonication for 30 seconds using a Branson Digital Sonifier Model 250-D at 10\% of its maximum force. The sample was subsequently clarified by centrifugating for 30 seconds at $10,000 \mathrm{x} g$ in a tabletop centrifuge (Eppendorf, Hamburg, Germany). The obtained super- 
Table 1. S. oneidensis MR-1 proteins applied in this study.

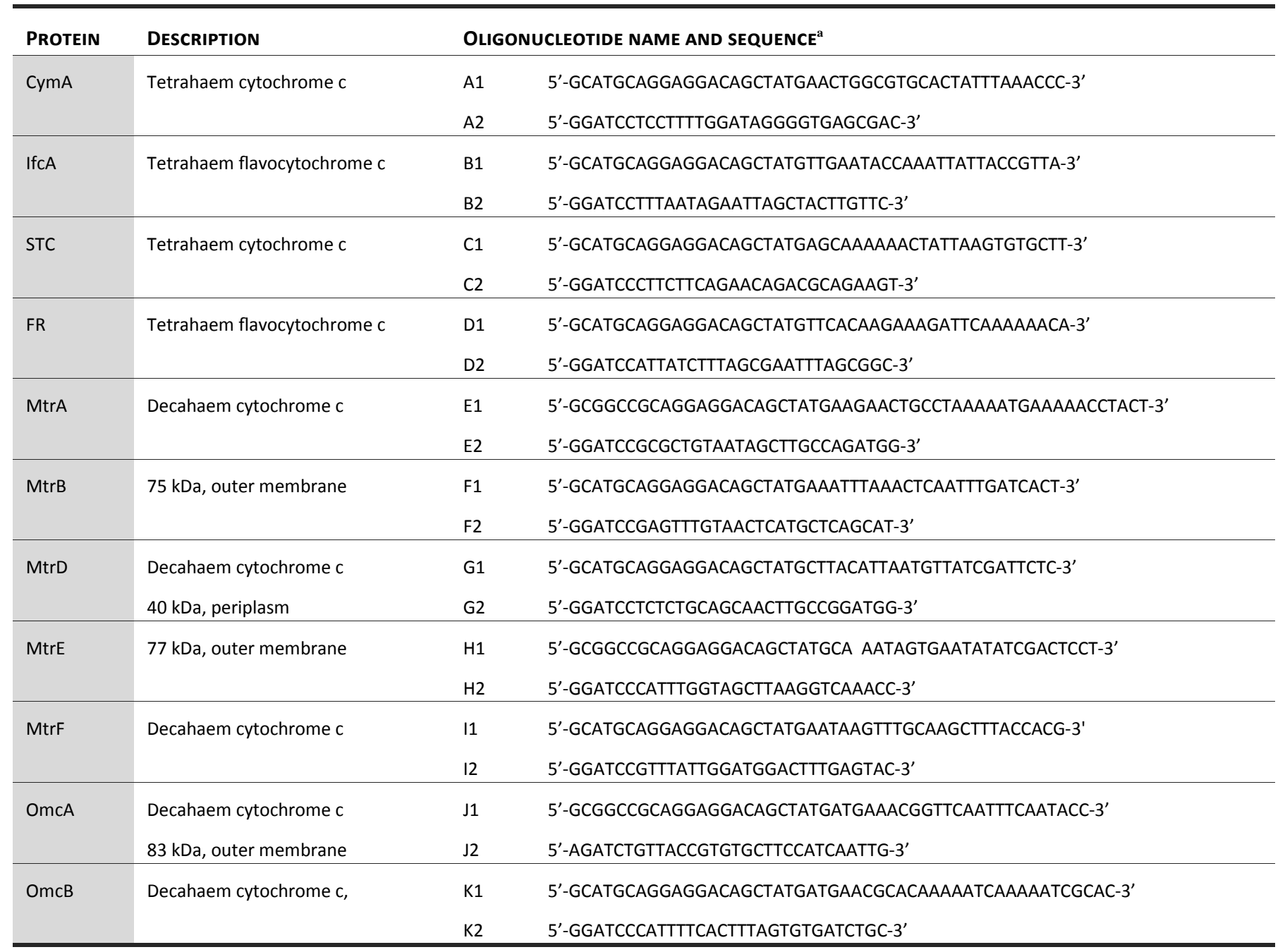

a Underlined regions indicate the added restriction endonuclease sites to facilitate cloning: BamHI for A2, B2, C2, D2, E2, F2, G2, I2 and K2; SphI for A1, B1, C1, D1, F1, G1, I1 and K1; NotI for E1, H1 and J1; BglII for J2

natant was used in the assay.

$\beta$-Galactosidase activity was assayed quantitatively at room temperature by following ONPG hydrolysis and 2nitrophenol formation at $415 \mathrm{~nm}$ in a Bio-Rad model 680 microplate reader (Bio-Rad, Hercules, CA), in a total volume of $200 \mu \mathrm{L}$ using $\beta$-Galactosidase Assay Buffer (Pierce, Rockford, IL, USA). Half of the volume was protein sample while the other half consisted of the $\beta$-galactosidase substrate ONPG. Spectrophotometric measurements were started immediately after mixing. All values were subsequently normalized toward the total protein content per sample. The experiment was repeated five times for every fusion protein couple.

During analyses, an internal NIF set was used consisting of the fusion protein couple AtpE- $\Delta \alpha$ and AtpB- $\Delta \omega$ [19]. The $\beta$ -galactosidase activity value of this NIF set was $3.49 \pm 2.62$ $\mathrm{nmol} /(\mathrm{min} . \mathrm{mg})$ and is arbitrarily represented here as $1.00 \pm$ 0.75 . The activity levels of the analyzed fusion protein couples were subsequently expressed relative toward this NIF set (Table 2).

\subsection{Statistical Analysis}

In the application of the two-hybrid system, statistical analysis was used to attribute IF and NIF status to different sets of fusion protein couples. Since only comparisons between the mean values of small data sets were made, the student $t$-test was applied. Since we expected the IF sets to have at least an equal or larger mean value ( $\beta$-galactosidase activity) than the NIF sets, on the one hand, combined with the fact that a larger mean value for the NIF sets compared to the IF sets can only be attributed to chance, on the other hand, it was appropriate to choose a one-tail P-value. For all two-hybrid experiments, $n=5$ and the alpha level ( $a$-level) was set at 0.05 . All statistical analyses were carried out using GraphPad Prism Version 4.00 and on-line GraphPad statistical software (GraphPad Software, Inc., San Diego, CA, USA).

\subsection{Chemical Cross-linking}

S. oneidensis MR-1R was grown to mid-log phase in mini- 
Table 2. $\beta$-Galactosidase based two-hybrid analysis results a

\begin{tabular}{|c|c|c|c|c|c|c|c|c|c|c|c|}
\hline & CymA & IfcA & STC & FR & MtrA & MtrD & MtrB & MtrE & OmcA & OmcB & MtrF \\
\hline CymA & + & & & & & & & & & & \\
\hline IfcA & + & - & & & & & & & & & \\
\hline STC & - & - & - & & & & & & & & \\
\hline FR & ++ & ++ & + & ++ & & & & & & & \\
\hline MtrA & ++ & ++ & ++ & ++ & ++ & & & & & & \\
\hline MtrD & + & ++ & - & ++ & ++ & ++ & & & & & \\
\hline MtrB & - & - & - & - & ++ & + & - & & & & \\
\hline MtrE & - & - & - & - & + & - & - & - & & & \\
\hline OmcA & - & - & - & - & ++ & ++ & ++ & ++ & - & & \\
\hline OmcB & - & - & - & - & + & ++ & ++ & ++ & ++ & - & \\
\hline MtrF & - & - & - & - & - & ++ & - & + & - & - & - \\
\hline
\end{tabular}

mal medium [11] with $20 \mathrm{mM}$ lactate and $50 \mathrm{mM}$ ferric citrate as the electron donor and acceptor, respectively. Cells were centrifuged at $16,000 \times \mathrm{g}$ for 1 minute and then washed with an equal volume of phosphate buffered saline (PBS, $\mathrm{pH}$ 7.0) before suspending them in PBS to an optical density of 0.4 at $550 \mathrm{~nm}$. Cells were cross-linked for 1 hour at room temperature with $1 \%$ formaldehyde. Following cross-linking, the total membrane fraction was prepared for both crosslinked and non-cross-linked cells, as described previously [19]. Equal amounts of the resulting samples were loaded on a $12 \%$ SDS-PAGE gel for analysis. After running the gel, it was stained specific for haem containing proteins as described by Thomas et al. [22]. The protein content of the resulting bands was subsequently analyzed by MALDI-TOF mass spectrometry.

\subsection{SDS-PAGE, Western Blotting and Haem Staining Anal- yses}

Protein content was verified by denaturing protein gel electrophoresis (SDS-PAGE) in 12\% gels according to the method of Laemmli [24]. Western blotting using an antibody specific for $\beta$-galactosidase from $E$. coli (Invitrogen; Carlsbad, CA, USA) was performed by blotting the proteins to a Hybond ECL membrane for 4 hours at $40 \mathrm{~V}$ followed by an overnight non-fat dry milk blocking step at $4^{\circ} \mathrm{C}$, extensive washing with PBS $+0.1 \%$ Tween 20 , and incubating the membrane with the anti- $\beta$-galactosidase antibody for 1 hour at room temperature. The washing steps were repeated and the membrane was subsequently incubated with horse raddish peroxidase (HRP) coupled to an antibody raised against the anti- $\beta$-galactosidase antibody. HRP chemiluminescence was then used to detect the fusion proteins containing the $\beta$ galactosidase fragments. Staining specific for haem containing proteins was carried out as described by Thomas et al. [22]. For all analyses, equal amounts of total protein (approx.
$20 \mu \mathrm{g})$ were consistently loaded on the gels.

\subsection{Miscellaneous Procedures}

Protein concentrations were determined by the Bradford assay [23] using the Bio-Rad Protein Assay Solution (BioRad, Hercules, CA, USA). Image acquisition was carried out using software packages Corel $^{\circledR}$ version 9 and Paintshop Pro version 5 (Corel, Berkshire, UK).

\section{Results}

\subsection{Fe(III)-NTA Reduction Activity of the Insertion Mutants.}

When comparing to $S$. oneidensis MR-1R, the STC insertion mutant has its $\mathrm{Fe}$ (III)-NTA reduction capacity being diminished by approximately $40 \%$ (Fig. 1). Disrupting the $o m c A, F R$, ifc $A, m t r D$ and $m t r F$ genes leads to a slight drop in $\mathrm{Fe}$ (III)-NTA reduction activity, of approx. $10 \%$. Whereas the $o m c B$ and $c y m A$ mutants still bear some residual reduction activity (10\% of the MR-1R level at most), disrupting $m \operatorname{tr} A$ and $m t r B$ almost completely abolishes Fe(III)-NTA reduction. Figure 1 also shows that when two (often modulatory) genes are simultaneously interrupted, particularly the omcA/omcB, $m \operatorname{tr} A / m \operatorname{tr} D, m \operatorname{tr} B / m \operatorname{tr} E, m \operatorname{tr} B / m \operatorname{trF}$ and $o m c B /$ $m t r F$ double mutants, no significant levels of reduction activities are observed either. Importantly, a $c c m E$ mutant (CcmE, SO_0259), which is defective in cytochrome $c$ maturation, also lacks $\mathrm{Fe}(\mathrm{III})$-NTA reduction activity

\section{2 $\beta$-Galactosidase-based Bacterial Two-Hybrid Assay}

To assess their protein-protein interaction behaviour, $c y$ $m A, F R$, ifc $A, S T C, m t r A, m t r B, m t r D, m t r E, m t r F, o m c A$ and $o m c B$ were all separately cloned both into the $\mathrm{pB} 2 \mathrm{H} \Delta \alpha$ and $\mathrm{pB} 2 \mathrm{H} \Delta \omega$ constructs as described previously [19]. A list of 


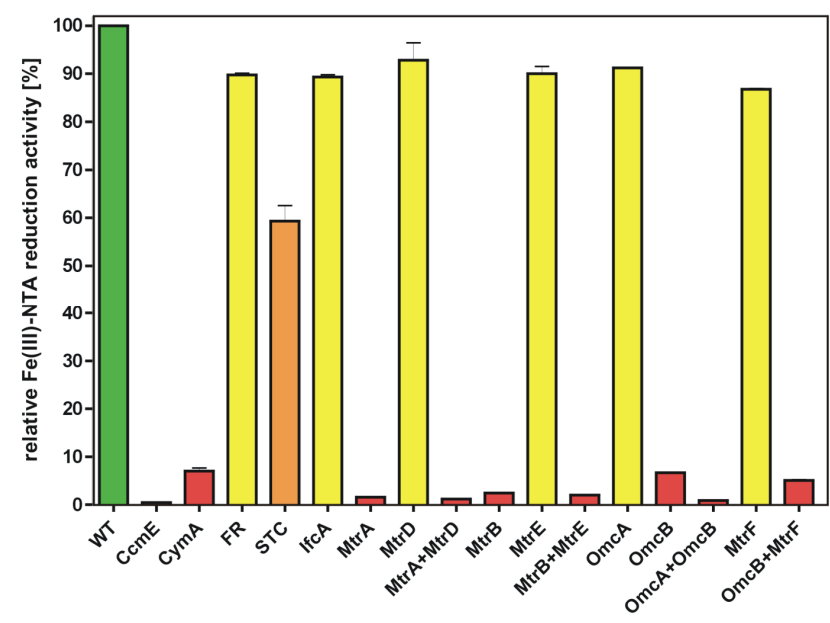

Figure 1. Fe(III)-NTA reduction assay of the mutants. Bar representation of the Fe(III)-NTA reduction activities of the single and double insertion mutants applied in this study. Values are presented relative to the reduction capacity of $S$. oneidensis MR-1R, for which the level was set at $100 \%$. Error bars indicate the standard error of the mean (SEM).

these proteins and their as of yet known properties is provided in Table 1.

Correct synthesis of the fusion proteins was controlled by Western blotting (immunoblot) for those containing MtrB and MtrE, and haem staining for those carrying haemproteins. Figure 2 shows the expression results for $\mathrm{pB} 2 \mathrm{H} \Delta \alpha-$ containing fusion proteins. Haem staining reveals successful haem attachment for all haem-carrying fusion proteins after proper translocation to the periplasm (Fig. 2A). The immunodetection using anti- $\beta$-galactosidase antibodies verified that the MtrB- and MtrE-containing chimeras are properly
A

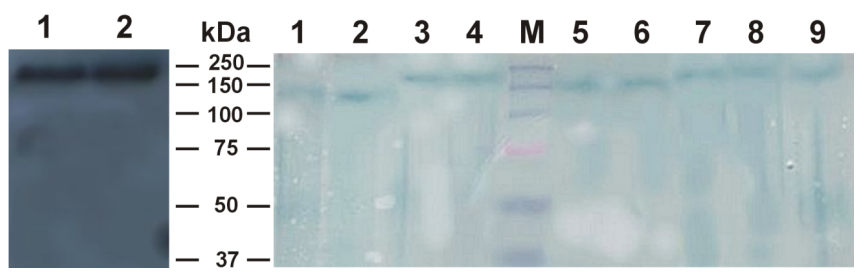

Figure 2. Controls regarding the proper synthesis of the fusion proteins. A. Western blot using an antibody specific for $\beta$ galactosidase, equal amounts of protein were loaded $(\sim 20 \mu \mathrm{g}$ total protein). The molecular weight marker is indicated at the centre of the figure. Lane 1, pB2H $\Delta a \Omega m t r B ~(193 \mathrm{kDa})$; Lane 2, $\mathrm{pB} 2 \mathrm{H} \Delta a \Omega \mathrm{mtrE}(195 \mathrm{kDa})$. B. Specific staining for haem proteins, equal amounts of protein were loaded ( $\sim 20 \mu \mathrm{g}$ total protein). The molecular weight marker is indicated at the centre of the haemstained gel. Lane 1, pB2H $\Delta a \Omega c y m A ~(139 \mathrm{kDa})$; Lane 2, $\mathrm{pB} 2 \mathrm{H} \Delta \alpha \Omega S T C$ (132 kDa); Lane 3, pB2H $\Delta \alpha \Omega$ ifcA (183 kDa); Lane 4, pB2H $\Delta a \Omega F R(181 \mathrm{kDa})$; Lane 5, pB2H $\Delta a \Omega \operatorname{mtrA}(161 \mathrm{kDa})$; Lane 6, pB2H $\Delta \alpha \Omega$ trD (158 kDa); Lane 7, pB2H $\Delta \alpha \Omega \operatorname{mtrF}(192$ $\mathrm{kDa})$; Lane 8, pB2H $\Delta \alpha \Omega$ omcA $(201 \mathrm{kDa})$; Lane 9, $\mathrm{pB} 2 \mathrm{H} \Delta \alpha \Omega$ omcB $(195 \mathrm{kDa})$. synthesized at low, quasi physiological levels when IPTG is added to the growth medium (Fig. $2 B$ ).

Our two-hybrid analysis, the results of which are presented schematically in Figure 3, and in a complete though condensed form in Table 2, reveals the interaction of the cytoplasmic membrane-anchored CymA with itself and with the periplasm-located IfcA, FR and MtrA. The latter two display a strong interaction with CymA, whereas the MtrAparalogue MtrD surprisingly yielded no positive signal. The periplasmic pool, consisting of the multi-haem c-type cytochromes IfcA, STC, FR, MtrA and MtrD, furthermore reveal an extensive divergence of interactions, that is, besides IfcA interacting with FR, both of these proteins interact strongly with MtrA and its paralogue MtrD. In contrast, STC seems to be more limited in its interaction behaviour since it only interacts with FR and MtrA. Of the periplasmic proteins, FR and MtrA both exhibit positive interaction values with all other periplasm-directed cytochromes, and with themselves. However, given their interaction profiles with the outer membrane localized proteins MtrB, MtrE, OmcA and $\mathrm{OmcB}$, apparently only MtrA, and to a lesser extent MtrD, are capable of making the link to the membranous protein pool. MtrB and its paralogue MtrE were additionally identified as to strongly interact with both OmcA and OmcB. Finally, although not found to form homo-oligomers, a convincingly positive interaction signal was also observed when the terminal ferric reductases $\mathrm{OmcA}$ and $\mathrm{OmcB}$ were coexpressed.

\subsection{Chemical cross-linking.}

The membrane fractions of both formaldehyde crosslinked and non-cross-linked S. oneidensis MR-1R cells were applied to SDS-PAGE and visualized by haem-staining. The gel showed two prominent bands of 80 and $73 \mathrm{kDa}$ (Fig. 4) corresponding to OmcA and $\mathrm{OmcB}$, respectively. Addition of $1 \%$ formaldehyde to undisrupted cells resulted in the appearance of a new haem band corresponding to a molecular weight of approximately $200 \mathrm{kDa}$, as shown in Figure 4 . MALDI-TOF mass spectrometric analysis identified the cross-linked proteins as OmcA, OmcB and MtrB, which is in accordance with the observed molecular weight of the proteins on the haem-stained gel.

\section{Discussion}

The fundamental importance of cytochromes $c$ in anaerobic metal reduction has been recognized for quite some years $[4,25,26]$ and is here confirmed through our experiments in that a S. oneidensis MR-1 mutant defective in cytochrome $c$ maturation ( $\mathrm{ccmE}$ mutant) does not hold any significant $\mathrm{Fe}$ (III)-NTA reduction activity (Fig. 1).

The central position of CymA (Fig. 3), being cytoplasmic membrane-anchored and faced to the periplasm, already suggests its pivotal role in the electron transfer process. This is again reflected by the lack of any substantial Fe(III)-NTA 


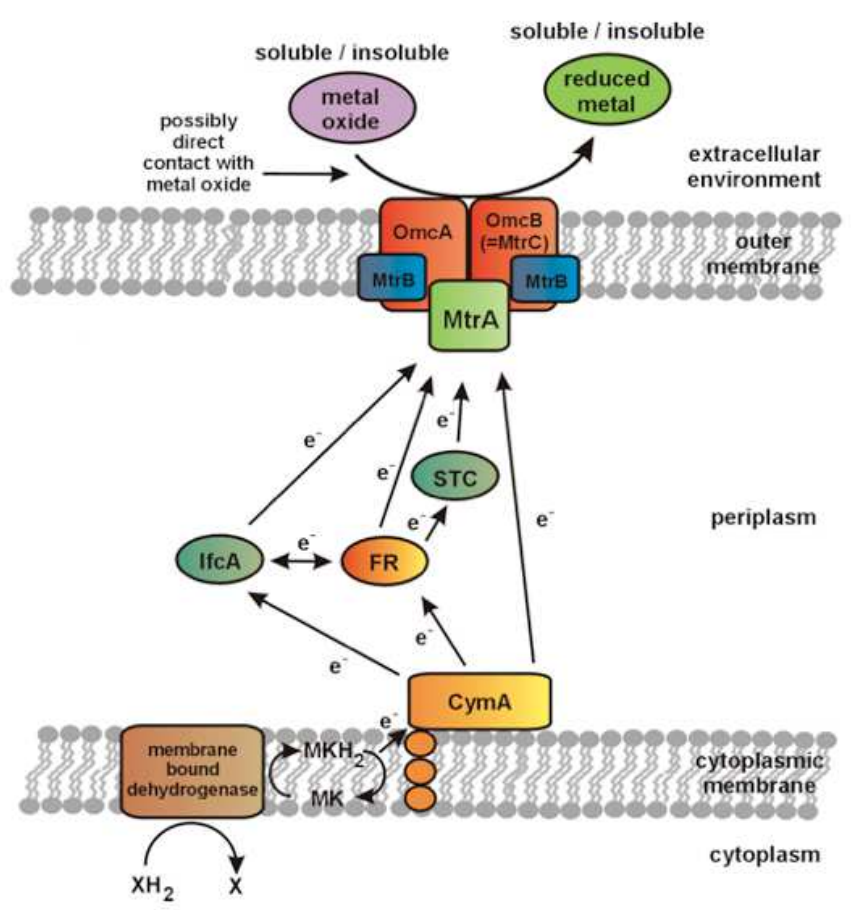

Figure 3. Model for the metal reduction mechanism by S. oneidensis $M R-1$. The arrows indicate the possible routes of electron transfer starting from the cytoplasm, via the cytoplasmic membrane, periplasm and outer membrane, and ending at the reduction of the targetted metal species. See text for further details.

reduction capacity of the cymA mutant. The fact that it interacts with all periplasmic components of the electron transport chain, except with STC, is decisive in our conclu-

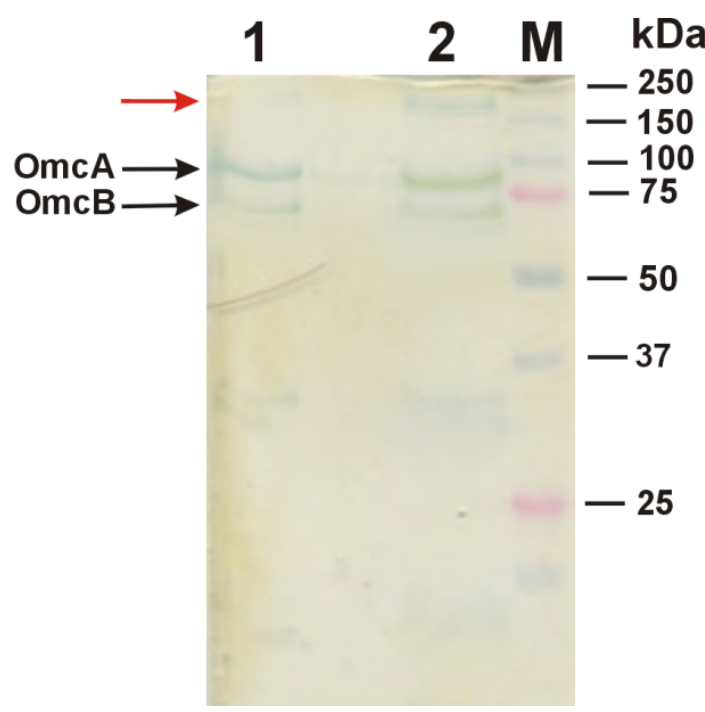

Figure 4. Heme-stain after the formaldehyde cross-linking experiment. Total membrane fractions originating from non-crosslinked S. oneidensis MR-1R cells (Lane 1), and formaldehyde cross -linked cells (Lane 2). Black arrows specify the positions of OmcA and $\mathrm{OmcB}$, whereas the red arrow indicates the cross-linked highmolecular weight species observed only in Lane 2 . The molecular weight marker is indicated on the right in units of $\mathrm{kDa}$. sion that CymA, apparently as a homo-oligomer, forms the crucial link between the menaquinone pool in the cytoplasmic membrane and the several periplasmic electron transfer proteins, which is in agreement with previous studies $[14,27]$. From CymA onwards, the electron transport chain further branches off towards three periplasmic electron transporters, i.e. IfcA, FR and MtrA (Fig. 3), of which the latter seems to take the leading role, given the effect of disrupting the mtrA gene on Fe(III)-NTA reduction (Fig. 1). The redundancy of IfcA and FR in the electron transfer cascade is reflected by i) the minor decrease in Fe(III)-NTA reduction activity that is observed when disrupting the respective genes (Fig. 1), and ii) the fact that both IfcA and FR interact with each other and, more importantly, with MtrA (and its paralogue MtrD). This indicates that after the bifurcation, the electron transport chain again congregates at some point, more particularly, at the key component MtrA, as was also proposed by Coursolle and Gralnick [14].

In Shewanella frigidimarina the iron-induced flavocytochrome $c_{3}$ is coded by the IfcA gene, and although it displays fumarate reductase activity it is only induced when $S$. frigidimarina is grown on soluble Fe(III) [15]. Since IfcA might behave similarly in S. oneidensis MR-1, its redundancy in the electron transport chain seems plausible. Previous reports that If $_{3}$ forms dimmers in the psychrophilic S. frigidimarina [14] cannot be supported by our study of the S. oneidensis MR-1 IfcA.

Besides its previously reported [17] and in the present study confirmed interaction with CymA, the soluble fumarate reductase (FR) is one of two periplasmic proteins (the other being MtrA) that interacts with the small tetrahaem cytochrome $c$ (STC), indicating yet another point where the electron transfer cascade splits up. This noncentral position of STC, together with the limited effect in Fe (III)-NTA reduction observed from the STC S. oneidensis MR-1 mutant strain, makes us deduce that STC plays a secondary role in anaerobic metal respiration.

From the results given in Table 2 it is clear that MtrA, and to a lesser extent its paralogue MtrD, functions as the central electron courier in the periplasm, possibly as a homooligomer and as part of a greater outer membrane-associated complex, thus corroborating the observations made by Ross et al. [27,28]. This, together with the total loss of Fe(III)NTA reduction activity in the $m t r A$ mutant (but not in the $m t r D$ mutant), is in contrast to earlier reports which stated that membrane fractions of a $m t r A$ deletion mutant were still able to reduce $\mathrm{Fe}(\mathrm{III})$-oxides [2].

Making a bridge from the periplasm to the outer membrane, we find MtrA again playing a decisive role in that it clearly interacts with the outer membrane situated $\beta$ barrel porin MtrB. These findings are in line with those of Ross et al. [28] and Hartshorne et al. [9], the latter of whom attribute a sheath-like role to MtrB, enabling it to transfer electrons from the periplasmic MtrA to the outer membrane -situated MtrC (= OmcB). Besides such crucial task and the fact that it serves as a component responsible for anchoring 
or orienting proteins in/to the outer membrane [10], chances that MtrB and MtrE would serve as an electron transporter are inexistent, since they carry no haem or any other redox-active moieties. The presence or absence of MtrB thus indirectly affects the ability of $S$. oneidensis reducing certain electron acceptors, a statement that is corroborated by the results of our Fe(III)-NTA reduction assays with the $m t r B$ mutant (Fig. 1). Surprisingly, the $m t r E$ mutation merely caused a $\sim 10 \%$ drop in Fe(III)-NTA reduction activity. Apart from MtrA and MtrB interacting, both proteins, and their paralogues $\mathrm{MtrD}$ and MtrE, displayed a positive interaction signal with both outer membrane localized decahaem cytochromes $c$ OmcA and $\operatorname{MtrC}(=\mathrm{OmcB})$, and the MtrC paralogue MtrF. Also hinted at other studies $[9,28]$, these results strengthen the theory that MtrA, MtrB, OmcA and MtrC might form a multicomponent complex that would be responsible for metal reduction. It should be noted at this point that, using the techniques that we applied ,no assumptions can be made concerning the stability of these interactions, since electron transfer only requires transient interactions (approx. $10^{-9} \mathrm{~s}$ ). Nevertheless, from our two-hybrid and cross-linking experiments we can deduce that the two outer-membrane decahaem cytochromes $c$ OmcA and MtrC interact and very likely form a stable complex, as was previously also suggested by Shi et al. [29]. Our results support their suggestion that OmcA and MtrC interact in a 2:1 ratio.

Even though the results of our two-hybrid analyses suggest that MtrD, MtrE and MtrF play significant roles in the electron transport chain, the $\mathrm{Fe}(\mathrm{III})-\mathrm{NTA}$ reduction assays refute this conclusion, since inactivating the respective genes brings the reduction activities down by only approximately $10 \%$ (Fig. 1). However, this seems logical, since their paralogues MtrA, MtrB and MtrC, respectively, are still present and take over their roles; a feature referred $t$ as the 'modularity' by Coursolle and Gralnick [14]. The lack of reduction activity in the $m \operatorname{tr} A, m \operatorname{tr} B$ and $o m c B$ mutants, in contrast, may find its origin in the low or non-expression of their respective paralogues.

\section{Concluding Remarks}

In conclusion, we have shown that our bacterial twohybrid system is a powerful tool in protein-protein interaction studies. As the case of S. oneidensis MR-1 exemplifies, anaerobic metal reduction was found to require cytoplasmic membrane, periplasmic and outer membrane components, the most important of which being CymA, MtrA and OmcA, MtrC and MtrB, respectively. It has previously been shown that OmcA and $\mathrm{OmcB}$ both function as terminal ferric reductases, the latter (MtrC) being the principal enzyme (Fig. 1) [11]. We believe therefore that the electron transport chain ends at the OmcA/MtrC complex, accompanied by MtrA and MtrB, and that the ultimate step in metal reduction is the transfer of electrons to the targetted metal species, as is depicted in Figure 3.

\section{Acknowledgements}

This work was supported by a personal grant to J.B. from the Institute for the Promotion of Innovation by Science and Technology in Flanders (IWT-Vlaanderen). J.V.B. and B.D. are indebted to the Fund for Scientific Research (FWOVlaanderen) for granting research project G.0190.04, as well as to the Bijzonder Onderzoeksfonds of Ghent University for Concerted Research Action GOA 120154 and to BELSPO for funding IAP Grant PROFUSA. The authors are grateful to Bart Motte and Sarah De Keulenaer for technical help. We thank L. Thöny-Meyer for kindly providing us the pEC86 vector.

\section{References}

1. D. J. Lonergan, H. L. Jenter, J. D. Coates, E. J. Phillips, T. M. Schmidt, D. R. Lovley, J. Bacteriol. 178 (1996) 2402-2408.

2. D. R. Lovley, E. J. Phillips, App. Environ. Microbiol. 54 (1988) 1472-1480.

3. K. Venkateswaran, D. P. Moser, M. E. Dollhopf, D. P. Lies, D. A. Saffarini, B. J. MacGregor, D. B. Ringelberg, D. C. White, M. Nishijima, H. Sano, J. Burghardt, E. Stackebrandt, K. H. Nealson, Int. J. Sys. Bacteriol. 49 (1999) 705-724.

4. A. S. Beliaev, D. A. Saffarini, J. L. McLaughlin, D. Hunnicutt, Mol. Microbiol. 39 (2001) 722-730.

5. C. R. Myers, J. M. Myers, J. Bacteriol. 179 (1997) 1143-1152.

6. J. M. Myers, C. R. Myers, J. Bacteriol. 182 (2000) 67-75.

7. C. Schwalb, S. K. Chapman, G. A. Reid, Biochemistry 42 (2003) 9491-9497. DOI: 10.1021/bi034456f

8. A. S. Beliaev, D. A. Saffarini, J. Bacteriol. 180 (1998) 62926297.

9. R. S. Hartshorne, C. L. Reardon, D. Ross, J. Nuester, T. A. Clarke, A. J. Gates, P. C. Mills, J. K. Fredrickson, J. M. Zachara, L. Shi, A. S. Beliaev, M. J. Marshall, M. Tien, S. Brantley, J. N. Butt, D. J. Richardson, Proc. Nat. Acad.Sci. USA 106 (2009) 22169-22174. DOI: 10.1073/pnas.0900086106

10. C. R. Myers, J. M. Myers, Appl. Environ. Microbiol. 68 (2002) 5585-5594.

11. J. Borloo, B. Vergauwen, L. De Smet, A. Brige, B. Motte, B. Devreese, J. Van Beeumen, FEBS J. 274 (2007b) 3728-3738. DOI: $10.1111 /$ j.1742-4658.2007.05907.x

12. L. Shi, T. C. Squier, J. M. Zachara, J. K. Fredrickson, Mol. Microbiol. 65 (2007) 12-20. DOI: 10.1111/j.13652958.2007.05783.x

13. Y. Xiong, L. Shi, B. Chen, M. U. Mayer, B. H. Lower, Y. Londer, S. Bose, M. F. Hochella, J. K. Fredrickson, T. C. Squier, J. Am. Chem. Soc. 128 (2006) 13978-13979. DOI:10.1021/ ja063526d

14. D. Coursolle, J. A. Gralnick, Mol. Microbiol. 4 (2010) 9951008. DOI: $10.1111 /$ j.1365-2958.2010.07266.x

15. P. S. Dobbin, J. N. Butt, A. K. Powell, G. A. Reid, D. J. Richardson, Biochem. J. 342 (1999) 439-448.

16. D. Leys, T. E. Meyer, A. S. Tsapin, K. H. Nealson, M. A. Cusanovich, J. J. Van Beeumen, J.Biol. Chem. 277 (2002) 3570335711. DOI: $10.1074 /$ jbc.M203866200

17. A. I. Tsapin, I. Vandenberghe, K. H. Nealson, J. H. Scott, T. E. Meyer, M. A. Cusanovich, E. Harada, T. Kaizu, H. Akutsu, D. Leys, J. J. Van Beeumen, Appl. Environ. Microbiol. 67 (2001) 
3236-3244. DOI: 10.1128/AEM.67.7.3236-3244.2001

18. C. Schwalb, S. K. Chapman, G. A. Reid, Biochem. Soc. Trans. 30 (2002) 658-662. DOI: 10.1042/ bst0300658

19. J. Borloo, L. De Smet, B. Vergauwen, J. J. Van Beeumen, B. Devreese, J. Prot. Res. 6 (2007a) 6, 2587-2595. DOI: 10.1021/ pr070037j

20. A. Brige, B. Motte, J. Borloo, G. Buysschaert, B. Devreese, J. J. Van Beeumen, Micr. Biotech. 1 (2008) 40-52. DOI: 10.1111/ j.1751-7915.2007.00005.x

21. L. De Smet, G. W. Pettigrew, J. J. Van Beeumen, Eur. J. Biochem. 268 (2001) 6559-6568.

22. P. E. Thomas, D. Ryan, W. Levin, Anal. Biochem. 75 (1976) 168-176.

23. M. M. Bradford, Anal. Biochem. 72 (1976) 248-254.

24. U. K. Laemmli, Nature 227 (1970) 680-685.
25. C.R. Myers, J.M. Myers, FEMS Microbiol. Lett. 108 (1993) 1522.

26. C.R. Myers CR, J.M. Myers, J. Bacteriol. 179 (1997) 11431152.

27. D. E. Ross, J. M. Flynn, D. B. Baron, J. A. Gralnick, D. R. Bond, PloS one 6 (2011) e16649. DOI: 10.1371/ journal.pone.0016649.

28. D. E. Ross, S. S. Ruebush, S. L. Brantley, R. S. Hartshorne, T. A. Clarke, D. J. Richardson, M. Tien, Appl. Environ. Microbiol. 73 (2007) 5797-5808. DOI:10.1128/AEM.00146-07

29. L. Shi, B. Chen, Z. Wang, D. A. Elias, M. U. Mayer, Y. A. Gorby, S. Ni, B. H. Lower, D. W. Kennedy, D. S. Wunschel, H. M. Mottaz, M. J. Marshall, E. A. Hill, A. S. Beliaev, J. M. Zachara, J. K. Fredrickson, T. C. Squier, J. Bacteriol. 188 (2006) 4705-4714. DOI: 10.1128/JB.01966-05. 